\title{
Barriers to Quality of Care for Cancer Patients in Rural Areas: A Study from the Faroe Islands
}

This article was published in the following Dove Press journal:

Journal of Multidisciplinary Healthcare

\section{Birna Mohr Joensen (D) Sonja Nielsen $\mathbb{D}^{2}$ Ása Róin ${ }^{3}$}

'Naina, Recreation Home, Tórshavn, Faroe Islands; ${ }^{2}$ Department of Internal Medicine, National Hospital, Tórshavn, Faroe Islands; ${ }^{3}$ Department of Health and Nursing Science, University of the Faroe Islands, Tórshavn, Faroe Islands
Correspondence: Ása Róin

Department of Health and Nursing

Science, University of the Faroe Islands, P.

O. Box 272, 100, Tórshavn, Faroe Islands

$\mathrm{Tel}+298292254$

Email asar@setur.fo
Introduction: Research has indicated that cancer patients living in rural areas receive poorer quality of treatment and care than their urban counterparts. With a population of approximately 51,000, the Faroe Islands may be characterized as a small-scale, rural society. Due to the geographical location and size of the Faroe Islands, patients who live there often receive part of their treatment abroad. Although a shift in the focus of cancer care from a disease-focused approach to a person-centered approach has been successfully implemented elsewhere, legal and structural conditions unique to the Faroe Islands might prohibit the realization of this paradigmatic shift in the Faroe Islands. The aim of this qualitative study was to examine how Faroese cancer patients have experienced their disease, treatment, and care and provide additional knowledge on cancer patients living in small-scale and rural societies.

Methods: Five men and three women who had been through a cancer treatment course with a good prognosis volunteered to be interviewed. Their ages varied from 40 to 80 years. "Active interviewing”, a constructionist approach to qualitative interviewing and latent thematic analysis, was applied.

Results: Three overlapping themes were identified from the categories: sense of coherence, resources and challenges in everyday life, and trust in the system. The analysis uncovered multiple factors related to legal and structural conditions that were barriers to ensuring the quality of cancer care for patients, for instance, shifting consultants, a lack of coherence in treatment, information loss and insufficient contact with cancer nurse specialists.

Discussion: This study is based on a limited number of participants. However, the findings from this study provide insight into the special conditions of cancer patients living in a smallscale, rural society and help explain disparities in the quality of cancer treatment and care between urban and rural areas.

Keywords: cancer patients, quality of care, supportive care, small scale societies, rural areas, thematic analysis

\section{Introduction}

Cancer treatment has been through a paradigmatic shift from disease-focused management to a patient-centered approach, in which increasingly more attention is paid to the psychosocial aspects of treatment, such as quality of life, patients' rights, empowerment and survivorship. ${ }^{1}$ However, studies have shown disparities in the quality and care in cancer treatment between rural and urban areas. ${ }^{2-4}$ Most of these studies are from the United States, Australia and Canada, while studies within a European context are scarce. This study explores patient experiences in a Faroese context that differs in many ways from other contexts described in the literature. The Faroe Islands, an archipelago in the North Atlantic Ocean with approximately 
5100 inhabitants, are a small-scale society and rural, as far as access to specialized treatment possibilities is concerned. Patients diagnosed with cancer who live in the Faroe Islands most often have to travel abroad for treatment, either to Denmark or to Iceland, because no oncologist is employed, on a permanent basis on the Islands. An agreement is in place between The National Hospital in Copenhagen and The National Hospital in the Faroe Islands, which ensures that an oncologist comes 2 days a week. However, several different consultants are involved, which, as noted by King, ${ }^{5}$ might affect the continuity of treatment.

During the last 5 years, 226 patients were diagnosed with cancer each year, and in 2017, the number of times that patients were sent abroad for treatment was 459. While receiving treatment abroad, the patients stay in the provided patient hotels, often alone, without family members or friends. Only patients with a life-threatening disease or those at risk of severe side effects from chemotherapy receive financial support to bring a relative with them. ${ }^{6}$

Although several studies have investigated cancer treatment and care in rural areas using qualitative approaches, ${ }^{4}$ to our knowledge, qualitative studies conducted within a rural Scandinavian context are still wanted. The aim of this qualitative study was to examine how Faroese cancer patients have experienced their disease, treatment, and care and provide additional knowledge on cancer patients living in small-scale and rural societies.

\section{Background}

Several studies have pointed out disparities in health outcomes for individuals living in rural areas compared to those for individuals living in urban areas. ${ }^{2-4}$ In a mixedmethod study, Burris and Andrykowsky focused on mental health outcomes of rural and urban cancer survivors. ${ }^{3}$ They found that rural cancer patients experienced higher rates of anxiety, depressive symptoms, overall distress, and poorer mental health functioning and life satisfaction when compared to urban cancer patients.

A review from 2015 explored the impact of rural or remote residence on the supportive care needs of individuals living with cancer. ${ }^{4}$ The researchers included 23 articles from 2009 to 2014 . Only one study was conducted in a European country (Scotland), and all the others were from the US, Australia and Canada. The review revealed that individuals living with cancer in rural areas experienced a higher level of unmet needs than their urban counterparts. The qualitative study from Scotland ${ }^{7}$ explored how patients with colorectal cancer perceived their care. Additionally, the researchers compared the views and experiences of urban patients living in Aberdeen and Inverness, which have cancer treatment centers, with patients living in other parts of North and Northeast Scotland. The study showed that rural patients were less demanding than their urban counterparts when evaluating care and that problems related to transportation were largely accepted as inevitable. Conclusively, the authors recommended a person-centered approach to cancer patients that goes beyond the oftendominating standard protocols used in cancer care.

Qualitative studies have proven that supportive care, i.e., a person-centered approach to care, bolsters cancer patients' ability to cope with their disease and helps them navigate during their treatment continuum. ${ }^{8,9}$ Additionally, studies have pointed out that early supportive care intervention reduces the risk of extensive sick leave after treatment. $^{10-12}$

Cancer navigation, stemming from and in line with a person-centered approach, where healthcare professionals coordinate the treatment and care, has also proven valuable for patients. ${ }^{13,14}$ In addition, patient transfers between departments or hospitals, which are considered the riskiest procedure in the health-care system because of the unclear distribution of responsibilities and missing information about the patient, have been shown to benefit from using cancer navigators. ${ }^{15}$

\section{Method}

"Active interviewing", 16 a constructionist approach to qualitative interviewing, was used. The participants were asked to tell about their experiences, how they had felt physically, psychologically and socially during treatment, how they had managed in daily living and their thoughts about the future. The interviewer participated actively by asking elaborating questions, suggesting answers and interpretations. All interviews were tape-recorded in agreement with the participants and lasted from 25 to 50 mins. A pilot interview was conducted before the actual study. The team reflected on the outcome of the interview, especially related to the interviewer's communicative skills and ability to actively participate with leading questions. The first author conducted the interviews, made notes on the nonverbal expressions of the interviewees and transcribed the interviews verbatim. Afterwards, the co-authors listened to the recordings while reading the transcribed texts to obtain an impression of the atmosphere during the interview. 


\section{Participants}

With help from the Oncological Outpatient Clinic and the Office for Patient Transfer, cancer patients who had finished treatment with a good prognosis but were still following a control program were asked to participate. We were interested in both women and men and in obtaining variation regarding the type of treatment received. Patients in palliative treatment and patients diagnosed with dementia were excluded. After receiving information about the study, patients who had agreed to participate contacted us and further arrangements were made on how to meet. We included five women and three men with an age distribution of 40 to 80 years, representing different types of cancer and places of treatment (Table 1). The women preferred the interviews to take place in their homes, while the men preferred the interviewee's office as the interview location.

(Please place Table 1 here: overview of treatment and patient progress)

\section{Data Analysis}

The guidelines for conducting latent thematic analysis were used. ${ }^{17}$ The extracted passages were analyzed by searching for and coding issues of potential interest regarding what conditions the Faroese cancer patients found important for coping with challenges during treatment. After coding the issues of interest, we categorized the codes into themes by interpreting and identifying underlying ideas, assumptions and conceptualizations that were "theorized as shaping or informing the semantic content of the data" (ibid). Afterwards, the themes were reviewed to identify a logical coherent pattern from the extracted data set (ibid).

Antonovsky's concept of salutogenesis contributed to the process of identifying and interpreting the underlying ideas. A salutogenetic approach focuses on how an individual can manage a life with stress, danger and challenges. According to Antonovsky, the concept sense of coherence is central to successfully coping with challenges and consists of three elements: comprehensibility, manageability, and meaningfulness. ${ }^{18,19}$

\section{Ethical Considerations}

The study was conducted in accordance with the Helsinki Declarations ${ }^{20}$ and the ethical guidelines for nursing research in the north. ${ }^{21}$ Participants received written and oral information about the purpose of the study. They were guaranteed confidentiality, and anonymity was ensured by using pseudonyms for their names. They were also informed that they could withdraw at any time and for any reason. No formal ethical approval was necessary for the study according to the Research Ethical Board in the Faroe Islands. The participants all gave written consent to participate.

\section{Results}

We identified three themes that appeared to unite the initial codes and categories: sense of coherence, resources and challenges in everyday life and having trust in the system. The following transcription symbols are used in the excerpts: (.) indicates a short hesitation/pause in talk and (2) means a longer hesitation/pause in talk of, in this case, $2 \mathrm{~s}$.

Underlining a word means that the speaker puts stress on the word. () brackets indicate the author's comment and [] brackets indicate participants interrupting each other.

\section{Sense of Coherence}

The theme "sense of coherence" covered codes such as continuity, contact with professionals and how the

Table I Overview of Treatment and Patient Progress

\begin{tabular}{|c|c|c|c|c|c|c|c|c|}
\hline Interview & Laila & Durita & Dagny & lb & Sára & Sanna & Jens & Egil \\
\hline Chemo at outpatient clinic & $x$ & & & $x$ & $x$ & $x$ & & \\
\hline Chemo abroad & & & $x$ & $x$ & & $x$ & & \\
\hline Surgery on the FO & $x$ & $x$ & $x$ & & & & & \\
\hline Surgery abroad & & & & $x$ & $x$ & $x$ & $x$ & $x$ \\
\hline Radiation abroad & $x$ & $x$ & $x$ & & & & & $x$ \\
\hline Control at outpatient clinic & $x$ & $x$ & & & $x$ & $x$ & & \\
\hline Control at surgeons & & & & & & & $x$ & $x$ \\
\hline Control abroad & & & $x$ & $x$ & & $x$ & & \\
\hline Hospitalization due to complications & $x$ & & & $x$ & $x$ & $x$ & $x$ & \\
\hline Contact to Cancer Organization & & & & & & $x$ & $x$ & $x$ \\
\hline Granted relatives as travel companion & & & $\mathrm{x}$ & & $x$ & $x$ & & $x$ \\
\hline Start of control pathway & 2012 & 2012 & 2013 & 2017 & 2015 & 2017 & 2017 & 2016 \\
\hline
\end{tabular}


participants felt they were met by professionals. Circumstances related to the special Faroese conditions had an impact on the patient's sense of coherence. Although these circumstances also influenced the patients' trust in the system, we have included them in this part of the analysis.

The participants in our study had all completed their treatment and were now following a control program. Their experiences of treatment differed significantly, especially as they related to the type of cancer the patients suffered from, and whether the treatment had used surgical or medical management. For the participants with rare types of cancer, the treatment continuum appeared to lack continuity and coherence.

Jens, who suffered from a very rare type of cancer, experienced follow-up treatment in the Faroe Islands as lacking continuity and coherence. He expressed an unmet need of having a contact person in the Faroe Islands and a feeling of not belonging anywhere in the system compared to the other patients with more common types of cancer, especially because of varying consultants and the consultants having very little time for each patient.

Jens: Because I, you know (2) I mean that now I have heard from some (.) from others with different kinds of cancer and (2) and it appears that (1) certainly for those who belonged to a department or a specialist, who has been regularly on the Faroe Islands (.) they have had a lot closer relationship [yes?] than I had (.) and for that reason maybe been better informed, I suppose.

In contrast, Sanna, who had a more common type of cancer, experienced coherence and continuity during treatment in the Faroe Islands. She was affiliated with the oncological outpatient clinic and with a contact nurse.

Int: And this is on oncological ambulatory on the Faroe Islands?

Sanna: Yes.

Int: Yes (3) you feel like (1) they know you?

Sanna: And not just the one, where you say there is my nurse (3) but also those who walk in the hallway they say (.) hello (.) hello (.) are you here again (2), and you do not experience that in Rigshospitalet. (Danish National Hospital)

Only half of the participants in our study had been in contact with the medical outpatient clinic. Some of them had received control procedures abroad, whereas two had been referred to the surgical outpatient clinic without contact with the oncology nurses (Table 1).

For Sanna, the personal contact with the oncological nurses had meant a lot to her. She got quite emotional when talking about it:

Yeah (3), they are there (.) they see you (.) and they (.) listen to me (.) and they (.) take care of me.

According to Antonovsky, ${ }^{18}$ a salutogenetic approach questions why some people find the strength to recover despite stress and ailment. His concept "sense of coherence" suggests that to strengthen the human capacity or ability to master stress, it is important for the individual to be able to put the stress factors into a meaningful coherence. An example from our data showed how a participant, Egil, had experienced his treatment course to be planned and coherent and therefore meaningful. This had helped him cope with his disease and maintain his quality of life. Before surgery, he was offered prophylactic physiotherapy.

Egil: That's the first thing I should do (.) so I believe that's what's been my rescue right after the surgery in February (.) so in April I started to work and then I was fit for the fight, actually.

An important part of Antonovsky's concept sense of coherence relates to the practical component of manageability, which questions whether a person has the resources needed to cope with a serious disease and, often, a tough treatment course. This leads us to the next theme we found concerning resources and challenges in everyday life.

\section{Resources and Challenges in Everyday Life}

This theme addresses the participants' experiences regarding resources that had been important for them to cope with life with cancer and the challenges they had met.

During the interviews, all the participants spoke about the importance of having good networks. For instance, Laila said: All my children were around me (.) my husband was around me (.) I was never (.) eh (.) so to say lonely [no?] so I had the best backing (from the family). Sára, who experienced severe side effects from chemotherapy, including nausea and extreme tiredness, also related how having her husband with her always during treatment, had been of paramount importance for her for coping with these side effects.

Apart from the nearest relatives, networks also included friends and colleagues. 
Sanna: When I think about it eh (.) of course there are many small things that make up a (.) whole (.) but (.) this (.) this here (.) the safety network or what you feel (.) it is so terribly important, you know, like my colleagues, they (2) they made a kind of chain, you know (.) once a week, one would ring me, and then the next one would ring me. [Int: From your work?] Yes.

Only three out of the eight participants had contact with the Faroese Cancer Association and been to supportive group meetings. Egil was one of the interviewees who had benefited from joining a support group with other patients:

Egil: ... and then you get the possibility to talk to others and (.) they ask about different things (.) many do not have knowledge about the treatment they have had (.) then they can ask someone who has the experience, you know.

In their own ways, the participants had each experienced challenge related to their disease, treatment and the side effects of the treatment.

The challenges mostly related to mental strain, side effects from treatment as mentioned above, late-onset problems, and economical and geographic factors.

Worries about the future and anxiety about the recurrence of the cancer were the most common causes of mental strain:

Ib: I constantly think about (.) that ehm (.) is something that (.) can start to grow more

Sára: I have difficulties accepting that (1) I cannot do what I normally (.) used to do

One participant, Jens, described how he suddenly felt overwhelmed by fear, which manifested itself in physical symptoms:

Jens: But (1) like (.) psychological or in the mind I was fine, right? But then suddenly It started to eh (2) it was like something eh I do not know what it's called (.) post stress (.) or something like that could occur, right? [Hmhm] Then I started having trouble breathing. It was bad (.) came straight to the emergency room But they could immediately see that there was nothing wrong, I was fine breathing and they took all sorts of eh (.) blood samples and everything (.) put electrodes on me and everything was just fine, right? so it was just in my head, right? (1) Of course, it was a relief but also a little scary.

Extreme fatigue appeared to be a common side effect as well as late-onset symptoms from treatment. Sára was asked if she had experienced side effects during and/or after treatment:

Sára: ... well (2) I don't know if tiredness is one of them, but I have been extremely tired, I simply just can't get going again.

For Sanna, extreme fatigue was a well-known condition. However, she developed a coping strategy that helped her address this condition:

Sanna: ... and today has to be a good day, that there should not be (2) it should not spoil my day, you know, sometimes I am so tired and unable to do anything, but then I think about when I was really down, then I always thought, well, that's how it is today (.) just wait (.) it will not go on like this.

For some of the participants, economic aspects turned out to be an additional challenge. As mentioned in the Introduction, only patients with a life-threatening disease or patients at high risk of severe side effects from chemotherapy are granted financial support for a companion, most frequently a family member, to be with them. In cases where companions were not granted, some of the participants chose to finance their companions travel themselves.

Sanna: And she (1) was there for eh (1) I think she was there for about 8 weeks (2) and the stay on the patient hotel, I paid for that [Yes?] and I also paid for the children, when they came, and it was not cheap.

Our findings suggest that economic challenges might expose some patients to additional strain and highlight unequal possibilities for having members of a patient's support network present when treated abroad.

\section{Having Trust in the System}

The arrangements with shifting oncologists in the Islands appeared to affect the way the Faroese cancer patients experienced, not only the treatment and care they had received but also their trust in the system. The interviews showed that the individual treatment courses were adjusted to the variable presence of oncological specialists from abroad.

Laila had experienced being subjected to an illprepared plan for surgery due to the use of foreign consultants: 
Laila: So the same day, you know (3) I was told that I was going to have the operation the same day (2) and I should go home and come back at five in the afternoon and bring my husband along (.) an Icelandic doctor was on the Islands [Yes?] and he was going back the next day (.) so it was a lot of information at the same time [yes], but I went out there again at five (.) and waited for quite a while for the good doctor (.) and then he came and (.) he said no, he was not going to operate because he (.) now he was getting ready for going back to Iceland so I should go home and (.) wait for three weeks (2) there we sat, you know (.) and we went home and nobody contacted us or anything like that (.) it was three tough weeks.

A feeling of randomness regarding her treatment had marked Durita's experience with varying consultants:

Durita: And then I came to a Dane and he says no, now it's us and now we do it our way (2) and I say okay (2), and he changed it again to this one (laughing) litrosol (.) I had taken at first, right? [hm] Started with litrosol, then tamoxifen and then again litrosol.

Int: All that because of shifting oncologists?

Durita: Yes (2) it is how it is.

Int: Yes.

Durita: So, you can become a little eh (2) I do not know

(2) it seems kind of random, does not it?

Int: Yes.

Durita: It depends on whom you meet.

The interviewees did not directly express discontent regarding changing consultants. However, expressions of feeling lucky when a specialist was available were frequent. Jens, for instance, mentioned that he was fortunate because "a urologist was in the Faroe Islands that week".

The interviewees pointed out that information about their illness, treatment, prognoses and consequences regarding their everyday life had been crucial. Comprehensibility is one of the concepts included in Antonovsky's ${ }^{18}$ sense of coherence and hence salutogenesis. Jens, for instance, pointed out the importance of getting a comprehensible explanation for being able to cope with his disease:

Int: That was what the explanation was about...?

Jens: Yes (1) and (.) it was such a relief just to get an explanation (1) okay (.) this is terrible (.) but now I know why, right?

Int: Yes
Jens: So now I can accept it.

Our data revealed that trust in the system was at risk because information about the patients was lost or incorrect when the patients were transferred between departments and across national borders. Dagny explained how she had to contact the National Hospital before each control because she had experienced being "forgotten" or not receiving any follow-up call as she was supposed to. Jens, who had been through several transfers to Denmark and between departments, had experienced incidences where important information was lost during the transfer. He expressed his frustrations:

Jens: I do not know if it's only because I have such a rare form, or I had such a rare Form for cancer, that eh (.) but eh (.) I do not know (1) if I belong to someone, whom I (.) can always turn to, you know?

Int: Exactly, yes (2) so that is (1) that has characterized your course for the most part, right?

Jens: Yeah, that I am like only (1) an unknown patient who eh (.) floats between four different places in the health care system, right?

Insecurity might cause additional stress and influence a patient's coping ability. Confidence and security are important components in the perception of Antonovsky's ${ }^{18}$ concept of coherence, which forms an important part of the ability to cope with the challenges connected to life with cancer.

\section{Discussion and Conclusion}

Our findings point to several barriers to quality treatment and care for cancer patients living in the Faroe Islands, a small-scale, rural society. Most of these barriers were related to conditions known to characterize cancer treatment in rural areas such as the distance to cancer treatment centers, the lack of permanently employed oncologists and the unclear distribution of responsibility for the individual cancer patient's treatment. ${ }^{2,4,13}$

The consequences of these conditions had an impact on the participants' experiences. Some experienced their treatment course to be well organized and planned, while others experienced their pathway through treatment as unpredictable with multiple transitions and a lack of continuity and coherence. These differences have also been noted in studies from other rural areas. ${ }^{4,22}$ Martinez-Donate et al $^{13}$ have suggested that one way of compensating for the abovementioned barriers and challenges is to implement a cancer navigator system. A cancer navigator knows the system, acts as an expert in treatment courses, supervises and cares 
for the individual patient and creates continuity during treatment. Additionally, Hook et al found that a cancer navigator helped reduce inequalities in patient care and significantly improved patient satisfaction. ${ }^{22}$

Researchers have called attention to the importance of securing continuity in treatment by having one oncologist take responsibility as early as possible. ${ }^{5,14}$ With a system of shifting oncologists like the one in the Faroe Islands, this might seem difficult to implement. Our study shows that patients belonging to a surgical unit experienced a lack of continuity and felt insecure and a sense of not belonging anywhere. Patients affiliated with a medical department, on the other hand, with oncological nurse specialists, who could take care of them and pilot them through treatment, experienced a higher sense of belonging and continuity. One way of acting on the findings from this study would be to ensure that all cancer patients are offered contact with an oncology nurse specialist regardless of whether the patient belongs to a surgical or medical department. This could help to ensure that information about treatments and special needs are documented and passed on between consultants and during transfers.

Finally, our study highlights that there are unequal possibilities for having a member of the family present when being treated abroad. The premises for granting of a travel companion do not take into consideration age, problems with a foreign language or other personal circumstances. Consequently, economic challenges might expose some patients to additional strain, which Hubbard et al also found in a study among Scottish women with breast cancer. They concluded that cancer patients living in rural areas are worse off in many ways. ${ }^{23}$

The paradigm shift in cancer treatment and care from a disease-focused approach to a person-centered approach has not yet been realized in the Faroe Islands. We are aware that the number of participants in the present study is limited. However, the findings from this study provide insight into the special conditions of cancer patients living in a small-scale, rural society. The findings herein can help explain why the paradigm shift has not yet been realized and point out possible improvements that could reduce the disparities in the quality of cancer treatment and care between urban and rural areas.

\section{Disclosure}

The authors report no conflicts of interest in this work.

\section{References}

1. Borras J, Albreht T, Audisio R, et al. Policy statement on multidisciplinary cancer care. Eur $J$ Cancer. 2014;50:475-480. doi:10.1016/j.ejca.2013.11.012

2. Weaver K, Geiger AM, Lu L, Douglas Case L. Rural-urban disparities in health status among US cancer survivors. Cancer. 2013;119 (5):1050-1057. doi:10.1002/cncr.27840

3. Burris JL, Andrykowski M. Disparities in mental health between rural and nonrural survivor: a preliminary study. Psych Oncol. 2010;19(6):637-645. doi:10.1002/pon.1600

4. Lonhery J, Woodgate RL. Supportive care needs of rural individuals living with cancer: a literature review. Can Oncol Nurs J. 2015;25 (2):2368-8076. doi:10.5737/23688076252157166

5. King J, Ingham-Clarke C, Parker C, Jennings R, Leonard P. Towards saving a million bed days: reducing length of day through an acute oncology model of care for inpatients diagnosed as having cancer. BMJ Qual Saf. 2010;20(8):718-724. doi:10.1136/bmjqs.2010.044313

6. Løgtingslóg nr. 64 og Kunngerð nr [90Ministerial law number 64 and Bill number 90]; 2006. Available from: www.logir.fo. Accessed February 25, 2018.

7. Bain NS, Cambell NC, Ritchie LD, Cassidy J. Striking the right in colorectal cancer care - a qualitative study of rural and urban patients. Fam Pract. 2002;16(4):369-374. doi:10.1093/fampra/ 19.4.369

8. Fincham L, Copp G, Caldwell K, Jones L, Tookman A. Supportive care: experiences of cancer patients. Eur $J$ Oncol Nurs. 2005;9:258-268. doi:10.1016/j.ejon.2004.08.004

9. Malmstõm M, Klefsgård R, Johansson J, Ivarsson B. Patients'experiences of supportive care from a long-term perspective after oesophageal cancer surgery - a focus group study. Eur J Oncol Nurs. 2013;17 (6):856-862. doi:10.1016/j.ejon.2013.05.003

10. Larsson G, Mattson E, von Essen L. Aspects of quality of life, anxiety, and depression among persons diagnosed with cancer during adolescence: a long-term follow-up study. Eur $J$ Cancer. 2010;46:1062-1068. doi:10.1016/j.ejca.2010.01.021

11. Gudbergsson S, Torp S, Fløtten T, Fosså S, Nielsen R, Dahl A. A comparative study of cancer patients with short and long sick-leave after primary treatment. Acta Oncologic. 2011;50:381-389. doi:10.31 09/0284186X.2010.500298

12. Sarkar S, Sautier L, Schilling G, Bokemeyer C, Koch U, Mehnert A. Anxiety and fear of cancer recurrence and its association with supportive care needs and health-care service utilization in cancer patients. J Cancer Surviv. 2015;9:567-575. doi:10.1007/s11764015-0434-2

13. Martinez-Donate AP, Halverson J, Simon N, et al. Identifying health literacy and health system navigation needs among rural cancer patients: findings from the Rural Oncology Literacy Enhancement Study (ROLES). J Cancer Educ. 2013;28:573-581. doi:10.1007/ s13187-013-0505-x

14. Fillion L, Cook S, Veilette A, et al. Professional navigation framework: elaboration and validation in a canadian context. Oncol Nurs Forum. 2012;39(1):59-69. doi:10.1188/12.ONF.E58E69

15. Siemsen I, Michaelsen L, Nielsen J, Østergaard D, Andersen H. Der er mange sikkerhedsrisici ved patientovergange [There are many safety risks related to patient transitions]. Ugeskrift for læger [Weekly Doctors]. 2011;173:20.

16. Holstein AJ, Gubrium FJ. The Active Interview. Qualitative Research Methods Series. Thousand Oaks: Sage; 1995.

17. Braun V, Clarke V. Using thematic analysis in psychology. Qual Res Psychol. 2006;3(2):77-101. doi:10.1191/1478088706qp063oa

18. Antonovsky A. (Helbredets mysterie, at tåle stress og forblive rask) [Mystery of Health - To Manage Stress and Stay Healthy]. Copenhagen: Gyldendal Akademisk; 2003. 
19. Kvåle K, Synnes O. Understanding cancer patient's reflections on good nursing care in light of Antonovsky's theory. Eur J Oncol Nurs. 2013;17:814-819. doi:10.1016/j.ejon.2013.07.003

20. Available from: Wma.net https://www.wma.net/policies-post/wmadeclaration-of-helsinki-ethical-principles-for-medical-researchinvolving-human-subjects/. Accessed February 2, 2018.

21. Available from: ssn-norden.dk http://ssn-norden.dk/wp-content /uploads/2016/01/SSNs-etiske-retningslinjer.pdf. Accessed November $28,2018$.
22. Hook A, Ware L, Siler B, Packard A. Breast cancer navigation and patient satisfaction: exploring a community-based patient navigation model in rural setting. Oncol Nurs Forum. 2012;39(4):379-385. doi:10.1188/12.ONF.379-385

23. Hubbard G, Venning C, Walker A, Scannion K, Kaile R. Supportive care needs of women with breast cancer in rural Scotland. Support Care Cancer. 2015;23:1523-1532. doi:10.1007/ s00520-014-2501-z

\section{Publish your work in this journal}

The Journal of Multidisciplinary Healthcare is an international, peerreviewed open-access journal that aims to represent and publish research in healthcare areas delivered by practitioners of different disciplines. This includes studies and reviews conducted by multidisciplinary teams as well as research which evaluates the results or conduct of such teams or healthcare processes in general. The journal covers a very wide range of areas and welcomes submissions from practitioners at all levels, from all over the world. The manuscript management system is completely online and includes a very quick and fair peer-review system. Visit http://www.dovepress.com/testimonials. php to read real quotes from published authors. 